\title{
Sensitivitas dan Spesifisitas Pain, Incentive Spirometry, Cough Score sebagai Prediktor Acute Respiratory Distress Syndrome pada Pasien dengan Patah Tulang Iga akibat Trauma Tumpul Toraks
}

\section{Danny K. Rustandi, ${ }^{1}$ Adrian Tangkilisan, ${ }^{2}$ Wega Sukanto, ${ }^{2}$ Elfrida I. Marpaung ${ }^{3}$}

\author{
${ }^{1}$ Program Pendidikan Dokter Spesialis Bagian Ilmu Bedah Fakultas Kedokteran Universitas \\ Sam Ratulangi, Manado, Indonesia \\ ${ }^{2}$ Divisi Bedah Toraks Kardiovaskular Bagian Ilmu Bedah Fakultas Kedokteran Universitas \\ Sam Ratulangi - RSUP Prof. Dr. R. D. Kandou, Manado, Indonesia \\ ${ }^{3}$ Bagian Ilmu Kedokteran Fisik dan Rehabilitasi Fakultas Kedokteran Universitas Sam \\ Ratulangi - RSUP Prof. Dr. R. D. Kandou, Manado, Indonesia \\ Email: dannykristiantorustandi@yahoo.com
}

\begin{abstract}
Thoracic trauma is one of the most common causes of death in trauma cases due to acute respiratory distress syndrome (ARDS). Definitive diagnosis and rapid identification are challenges in ARDS due to blunt thoracic trauma. The PIC score (pain, incentive spirometry, cough) is used to evaluate and monitor patients during treatment. This study was aimed to assess the specificity and sensitivity of the PIC Score in predicting the occurrence of ARDS in patients with rib fractures due to blunt thoracic trauma. This study used a prospective cohort design with a correlation analysis using data of dependency modeling via R-line copula, ROC curve analysis, and regression analysis. The results showed a total of 25 patients with an average age of 52 years, male sex was predominant ( $84 \%$ vs $16 \%$ ). On admission, most patients had fractures of three ribs (40\%). The PIC score tended to be lower in patients with higher number of rib fractures. The relationship between the PIC score and the $\mathrm{PaO} / \mathrm{FiO} 2$ ratio on day 7 th of treatment showed a positive correlation, supporting the possibility of using the PIC score to predict ARDS. The sensitivity and specificity of the PIC score in predicting ARDS in blunt thoracic trauma were quite high (sensitivity $80.2 \%$ and specificity $80.9 \%$ ) with an accuracy of $80.9 \%$. In conclusion, the PIC score can predict accurately the occurrence of ARDS in patients with rib fractures due to blunt thoracic trauma.
\end{abstract}

Keywords: blunt thoracic trauma; ARDS; PIC score

\begin{abstract}
Abstrak: Trauma toraks merupakan salah satu penyebab kematian terbanyak dalam kasus trauma acute respiratory distress syndrome (ARDS). Diagnosis pasti dan identifikasi segera merupakan tantangan dalam penanganan ARDS akibat trauma tumpul toraks. PIC score (pain, incentive spirometry, cough) digunakan untuk mengevaluasi dan memonitor pasien selama perawatan. Penelitian ini bertujuan untuk menilai spesifisitas dan sensitivitas PIC score dalam memrediksi terjadinya ARDS pada pasien patah tulang iga akibat trauma tumpul toraks. Pada penelitian ini digunakan rancangan prospective cohort dengan penilaian korelasi analisis menggunakan data hasil pemodelan dependensi via $R$-line copula, analisis kurva ROC, dan analisis regresi. Hasil penelitian mendapatkan total 25 pasien dengan rerata usia 52 tahun, didominasi oleh laki-laki (84\% vs 16\%). Saat masuk kebanyakan pasien mengalami patah tulang pada tiga tulang iga (40\%). PIC score cenderung lebih rendah pada pasien dengan jumlah patah tulang iga yang lebih banyak. Hubungan antara PIC score dan rasio $\mathrm{PaO} 2 / \mathrm{FiO} 2$ pada hari ke-7 perawatan menunjukkan adanya korelasi positif; hal ini mendukung kemungkinan penggunaan PIC score untuk memrediksi ARDS. Sensitivitas dan spesifisitas PIC score dalam memrediksi ARDS pada trauma tumpul toraks cukup tinggi (sensitivitas 80,2\% dan spesifisitas $80,9 \%$ ) dengan akurasi $80,9 \%$. Simpulan penelitian ini ialah PIC score dapat memrediksi terjadinya ARDS secara akurat pada pasien patah tulang iga akibat trauma tumpul toraks.
\end{abstract}

Kata kunci: trauma tumpul toraks; ARDS; PIC score 


\section{PENDAHULUAN}

Trauma toraks merupakan salah satu penyebab kematian terbanyak dalam kasus trauma dan tercatat mencapai $25 \%-50 \%$ pada semua kasus trauma. Di Indonesia sendiri kejadian kecelakaan lalu lintas (KLL) meningkat dalam jumlah maupun jenisnya dengan perkiraan angka kematian dari 5,1 juta pada tahun 1990 menjadi 8,4 juta pada tahun 2020 atau meningkat sebanyak $65 \% .^{1,2}$ Kematian paling banyak diakibatkan oleh gagal napas akut atau acute respiratory distress syndrome (ARDS). Kondisi ARDS yang diakibatkan trauma toraks mencapai $20 \%$, terutama pada pasien dengan trauma multipel. ${ }^{3}$

Diagnosis pasti dan identifikasi cepat masih merupakan sebuah tantangan dalam ARDS akibat trauma toraks ini. Hingga saat ini analisis gas darah arteri (AGDA) merupakan salah satu pengukuran dan pemeriksaan yang dipakai sebagai deteksi ARDS. ${ }^{4}$ Pain atau nyeri membuat pasien kesulitan bernapas pada trauma tumpul toraks dan merupakan salah satu penyebab ARDS. Incentive spirometry dapat melihat pengembangan paru dan deteksi atelektasis terutama pada patah tulang iga. Kemampuan cough atau batuk yang menurun juga merupakan salah satu penyebab ARDS. ${ }^{5-8}$ Pain, incentive spirometry, cough (PIC core) secara original yang dibuat oleh Wellspan York Hospital, York, Pennsylvania, USA digunakan untuk mengevaluasi dan memonitor pasien selama perawatan. ${ }^{9}$ Berdasarkan latar belakang yang telah dipaparkan maka dilakukan penelitian ini yang bertujuan untuk menilai spesifisitas dan sensitivitas PIC score dalam memrediksi terjadinya ARDS pada pasien patah tulang iga akibat trauma tumpul toraks.

\section{METODE PENELITIAN}

Penelitian ini menggunakan rancangan prospective cohort, dengan populasi studi pasien patah tulang iga akibat trauma tumpul toraks yang berobat ke RSUP Kandou pada periode penelitian. Kriteria inklusi ialah pasien patah tulang iga akibat trauma tumpul toraks, mengerti dan dapat mengikuti perintah, dan memberikan persetujuan tertulis untuk berpartisipasi dalam penelitian melalui lembar informed consent. Kriteria eksklusi meliputi riwayat trauma $\geq 48$ jam, terdapat tanda-tanda syok (tekanan darah sistol $<100$ $\mathrm{mmHg}$ ), trauma tembus toraks, memerlukan intubasi, memerlukan tindakan invasif atau operasi darurat, didiagnosis atau dicuri-gai memiliki kondisi paru seperti pneumonia, tuberkulosis, atau tanda-tanda infeksi Covid19. Analisis data dilakukan dengan penilaian korelasi analisis menggunakan data hasil pemodelan dependensi via $R$-line copula. Analisis kurva ROC dilakukan untuk menentukan titik potong optimal PIC Score dalam mendeteksi ARDS. Analisis multivariat dilakukan dengan model analisis regresi. Analisis data dilakukan dengan menggunakan software statistik R versi 4.0.5.

\section{HASIL PENELITIAN}

Pada penelitian ini didapatkan total 25 pasien yang memenuhi kriteria inklusi dan eksklusi. Rerata usia pasien ialah 52 tahun namun variasinya cukup besar, yakni kurang lebih 13 tahun (Tabel 1), didominasi oleh pasien laki-laki ( $84 \%$ vs $16 \%$ ). Median tinggi badan pasien ialah $168 \mathrm{~cm}$ (IQR 165-170) $\mathrm{cm}$, sedangkan rerata berat badan ialah 67,1 $\mathrm{kg}( \pm 4,6 \mathrm{~kg})$.

Gambar 1 memperlihatkan bahwa PIC score berhubungan dengan rasio $\mathrm{PaO} 2$ /FiO2 saat 25 pasien masuk rumah sakit. Hasil distratifikasi menurut total patah tulang iga dengan menggunakan data hasil pemodelan dependensi via $R$-Vine Copula CATATAN: $* * p<0,01$ dan $* * * \mathrm{p}<0,001$.

Gambar 2 memperlihatkan bahwa dalam diskriminasi keadaan ARDS saat pasien masuk, area di bawah kurva (area under the curve/AUC) mencapai $92 \%$ dengan sensitivitas dan spesifisitas pada titik potong skor PIC 6,9 masing-masing sebesar 86\% dan $89 \%$. Hasil analisis menunjukkan bahwa titik potong optimal berada pada skor PIC 7,6 di mana pada nilai tersebut diperoleh sensitivitas $80 \%$ dan spesifisitas $81 \%$, sementara akurasi mencapai $81 \%$, PPV 18\%, dan NPV 99\%. Secara keseluruhan, AUC penggunaan skor PIC dalam memrediksi ARDS dalam tujuh hari perawatan sebesar $87 \%$. 
Tabel 1. Karakteristik pasien dalam penelitian $(\mathrm{N}=25)$

\begin{tabular}{|c|c|c|c|}
\hline Karakteristik & Mean \pm SD & Median (Q1-Q3) & $\mathrm{n}(\%)$ \\
\hline Usia & $51.6 \pm 13.4$ & $*$ & $*$ \\
\hline \multicolumn{4}{|l|}{ Kelamin } \\
\hline Laki-laki & $*$ & $*$ & $21(84)$ \\
\hline Perempuan & $*$ & $*$ & $4(16)$ \\
\hline Tinggi badan $(\mathrm{cm})$ & $*$ & $168.0(165.0-170.0)$ & $*$ \\
\hline Berat badan $(\mathrm{kg})$ & $67.1 \pm 4.6$ & $*$ & $*$ \\
\hline \multicolumn{4}{|l|}{ Keadaan masuk } \\
\hline Total patah tulang iga & $*$ & $3.0(2.0-4.0)$ & $*$ \\
\hline $1-2$ & $*$ & $*$ & $7(28)$ \\
\hline 3 & $*$ & $*$ & $10(40)$ \\
\hline $4-8$ & $*$ & $*$ & $8(32)$ \\
\hline \multicolumn{4}{|l|}{ Tulang iga yang terlibat ${ }^{\mathrm{a}}$} \\
\hline $\operatorname{Iga} 2$ & $*$ & $*$ & $5(20)$ \\
\hline Iga 3 & $*$ & $*$ & $14(56)$ \\
\hline Iga 4 & $*$ & $*$ & $17(68)$ \\
\hline Iga 5 & $*$ & $*$ & $17(68)$ \\
\hline Iga 6 & $*$ & $*$ & $11(44)$ \\
\hline Iga 7 & $*$ & $*$ & $9(36)$ \\
\hline Iga 8 & $*$ & $*$ & $6(24)$ \\
\hline Skor PIC & $*$ & $9.0(8.2-10.0)$ & $*$ \\
\hline $\mathrm{PaO}_{2} / \mathrm{FiO}_{2}$ & $*$ & $400.0(378.3-426.1)$ & $*$ \\
\hline ARDS & $*$ & $*$ & $1(4)$ \\
\hline \multicolumn{4}{|l|}{ Keadaan hari ke-7 } \\
\hline $\mathrm{PaO}_{2} / \mathrm{FiO}_{2}$ & $*$ & $404.3(388.0-426.1)$ & $*$ \\
\hline ARDS & $*$ & $*$ & $2(8)$ \\
\hline Meninggal & $*$ & $*$ & $4(16)$ \\
\hline
\end{tabular}

Catatan: SD, standar deviasi; Q1, kuartil I; Q3, kuartil III; PIC, pain, incentive spirometry, and cough; ${ }^{\text {a }}$ Dapat memiliki lebih dari satu kategori, tidak eksklusif

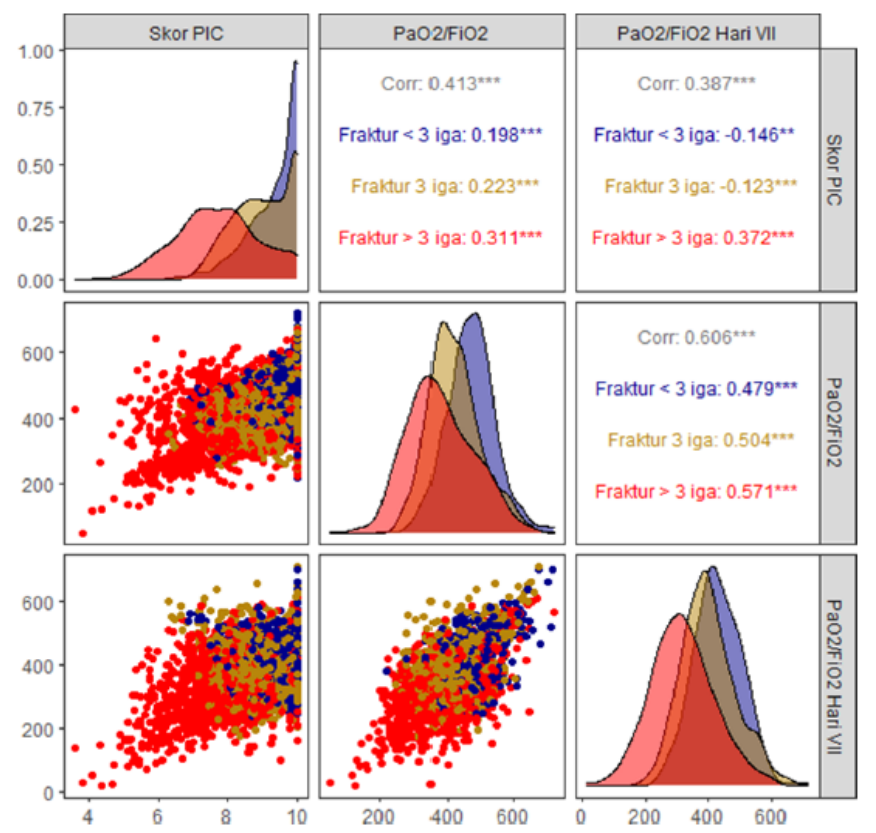

Gambar 1. Hubungan PIC score dengan rasio $\mathrm{PaO} 2 / \mathrm{FiO} 2$ saat 25 pasien masuk rumah sakit 

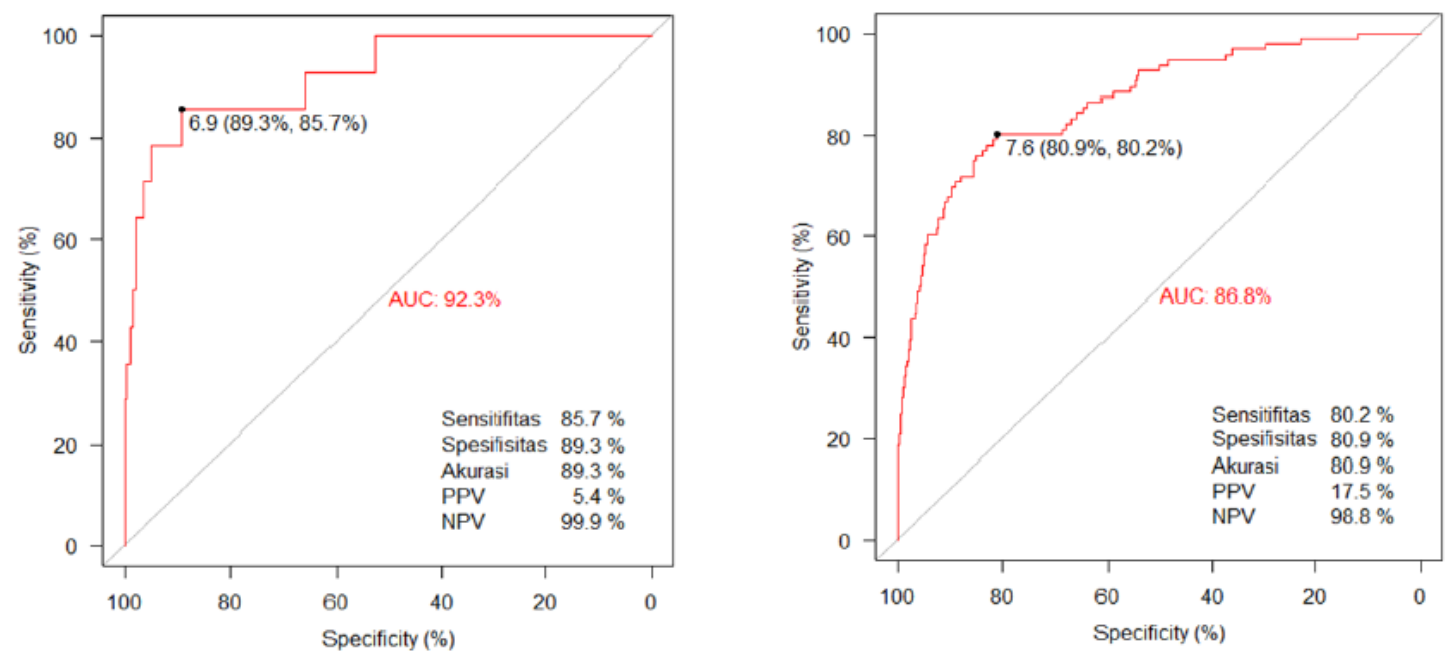

Gambar 2. Kurva Receiver Operating Characteristics Kemampuan PIC score dalam Diskriminasi (atas) dan Prediksi (bawah) ARDS pada patah tulang iga

Tabel 2. Model regresi logistik hubungan skor PIC (Prediktor) dan ARDS di Hari ke-7 (Outcome) $)^{a}$

\begin{tabular}{clcccc}
\hline Model Skor PIC & \multicolumn{2}{c}{ Model Univariabel $^{2}$ Model Multivariabel $^{b}$} \\
& & OR $(95 \%$ CI) & $\mathrm{p}$ & OR $(95 \%$ CI $)$ & $\mathrm{p}$ \\
\hline 1 & Skor PIC $<7,6$ & $16,47(9,84-27,55)$ & $<0,001$ & $5,29(3,07-9,13)$ & $<0,001$ \\
2 & Skor PIC $<6$ & $26,60(15,91-44,48)$ & $<0,001$ & $8,07(4,51-14,42)$ & $<0,001$ \\
3 & Skor PIC $<7$ & $20,08(12,75-31,64)$ & $<0,001$ & $6,21(3,78-10,18)$ & $<0,001$ \\
4 & Skor PIC $<8$ & $9,98(5,98-16,64)$ & $<0,001$ & $3,00(1,74-5,18)$ & $<0,001$ \\
\hline
\end{tabular}

OR, odds rasio; CI, confidence interval; ${ }^{a}$ Menggunakan data hasil pemodelan dependensi via $R$-Vine Copula ${ }^{b}$ Semua model multivariabel mengontrol nilai rasio $\mathrm{PaO}_{2} / \mathrm{FiO}_{2}$ masuk dan total patah tulang iga $(\leq 3$ atau $>3)$

Model PIC Score yang paling dekat hasilnya dengan model PIC Score <7,6 yang menjadi standar perbandingan ialah model PIC Score <7. Pada model regresi logistik ini, pasien patah tulang iga dengan PIC Score $<7$ memiliki odds ARDS dalam tujuh hari perawatan sekitar 20 (95\% CI 12,75$31,64)$ kali lipat lebih besar daripada yang dengan skor PIC $\geq 7$.

\section{BAHASAN}

Penelitian ini dilakukan secara prospective cohort terhadap pasien patah tulang iga akibat trauma tumpul toraks yang dirawat di RSUP Prof. Dr. R. D. Kandou Manado. Dari sampel yang terkumpul selama bulan September 2020 sampai dengan April 2021, diperoleh bahwa sebagian besar sampel berjenis kelamin laki-laki, berusia produktif, dan sebagian besar memiliki mobilitas tinggi dengan kendaraan bermotor. Profil ini sesuai dengan penyebab trauma tumpul toraks yang sebagian besar disebabkan oleh KLL. ${ }^{1,2}$

Sebanyak $40 \%$ pasien mengalami patah pada tiga tulang iga dan $32 \%$ patah pada empat sampai delapan tulang iga. Pada perhitungan PIC Score, nilai yang lebih rendah cenderung diperoleh pada pasien dengan jumlah patah iga yang lebih banyak. Hal ini berhubungan dengan kejadian peningkatan nyeri pada jumlah patah tulang iga yang lebih banyak akan menyebabkan penurunan kapasitas ventilasi dan perfusi, serta kemampuan batuk pasien. ${ }^{10-13}$ Matriks scatterplot dari korelasi antara PIC Score dan rasio $\mathrm{PaO}_{2} / \mathrm{FiO}_{2}$ pada hari ke-7 (Gambar 1) menunjukkan adanya hubungan positif 
antara keduanya. Hal ini mendukung kemungkinan penggunaan PIC score untuk memrediksi kejadian ARDS.

Kurva ROC dalam Gambar 2 menunjukkan kemampuan PIC score memrediksi ARDS dalam tujuh hari perawatan. Titik potong optimal berada pada pada skor PIC 7,6, dibulatkan menjadi 7; hal ini sejalan dengan penelitian Mastroianni ${ }^{14}$ yang menggunakan PIC score dengan titik potong 7 sebagai indikator perawatan ulang di ICU pada pasien patah tulang iga.

Hasil penelitian ini menunjukkan PIC score secara bermakna dapat digunakan sebagai prediktor kejadian ARDS. Sensitivitas dan spesifisitasnya dalam memrediksi ARDS pada trauma tumpul toraks sebesar $80,2 \%$ dan $80,9 \%$. Penelitian oleh Chang et $\mathrm{al}^{7}$ menggunakan PIC score dalam mendeteksi ARDS pada pasien patah tulang multipel untuk menilai keperluan alat bantu napas atau perawatan ICU sedangkan Mastroianni $^{14}$ menggunakan PIC score sebagai indikator perawatan ulang di ICU pada pasien patah tulang iga.

PIC score memiliki keunggulan dalam memrediksi ARDS pada pasien patah tulang iga dengan parameter meliputi penilaian nyeri (VAS), kekuatan inspirasi (spirometri insentif), dan kemampuan batuk (cough). Parameter yang ada mudah untuk dilakukan oleh klinisi di fasilitas kesehatan manapun. Oleh karena itu, PIC score dianjurkan untuk digunakan sebagai prediktor timbulnya ARDS pada kasus patah tulang iga akibat trauma tumpul toraks. Hal ini penting sebagai panduan manajemen awal dan keperluan ventilasi mekanik.

Penelitian ini memiliki keterbatasan berupa single centre study dan sebagai penelitian yang pertama kali dilakukan sehingga tidak terdapat pembanding dan sumber referensi sebelumnya.

\section{SIMPULAN}

PIC score dapat memprediksi terjadinya ARDS pada pasien patah tulang iga akibat trauma tumpul toraks, dengan sensitivitas $80,2 \%$, spesifisitas $80,9 \%$, dan akurasi $80,9 \%$. Melihat hasil ini PIC Score dapat dipakai sebagai salah satu alat prediktor terjadinya ARDS yang akurat pada kasus patah tulang iga akibat trauma tumpul toraks.

\section{Konflik Kepentingan}

Penulis menyatakan tidak terdapat konflik kepentingan dalam studi ini.

\section{DAFTAR PUSTAKA}

1. Handoyo C, Supriyanto E. Profil trauma thoraks di ruang rawat inap bedah RSUD Gambiran periode Maret 2017 - Maret 2018. Jurnal Ilmiah Kedokteran Wijaya Kusuma. 2018;7(2):178-88.

2. Pitojo KG, Tangkilisan A, Monoarfa A. Pola trauma tumpul toraks non penetrans, penanganan, dan hasil akhir di Instalasi Rawat Darurat Bedah RSUP Prof. Dr. R. D. Kandou Manado periode Januari 2014 - Juni 2016. e-Clinic. 2016;4(2).

3. Mason R, Broaddus V, Murray J, Nadel J. Murray \& Nadel's Textbook of Respiratory Medicine (4th ed) Chapters 85 and 86. Amsterdam: Elsevier Health Sciences, 2005.

4. Carlino MV, Guarino M, Izzo A, Carbone D, Arnone MI, Mancusi C, et al. Arterial blood gas analysis utility in predicting lung injury in blunt chest trauma. Respir Physiol Neurobiol. 2020;274:103363.

5. Ahn Y, Gorlinger K, Alam HB, Eikermann M. Case scenario: pain-associated respiratory failure in chest trauma. Anesthesiology. 2013;3(118):701-8.

6. Restrepo R, Wettstein R, Wittnebel L, Tracy M. Insentive Spirometry. Respir Care. 2011;56(10):1600-4.

7. Chang A. Feasibility of pain, insentive spirometry, cough (PIC) score [Thesis]. Texas: University of North Texas; 2016.

8. Sum, SK, Peng YC, Yin SY, Huang PF, Wang $\mathrm{YC}$, Chen TP, et al. Using an incentive spirometer reduces pulmonary complications in patients with traumatic rib fractures: a randomized controlled trial. Trials. 2019;20:797. Available from: https://doi.org/10.1186/s13063019-3943-x

9. Wit C, Bulger E. comprehensive approach to the management of the patient with multiple rib fractures: a review and introduction of a bundled rib fracture management protocol. BMJ. 2017;2(1):1-7.

10. Ludwig C, Korrylos A. Management of thoracic trauma. J Thorac Dis. 2017; 9(3):172-7. 
11. Kuo K, Kim A. Rib fracture. [Updated 2020 Nov 20]. In: StatPearls [Internet]. Treasure Island (FL): StatPearls Publishing; 2021 Jan-. Available from: https://www.ncbi.nlm.nih.gov/ books/NBK541020/

12. Bowman J, Jurkovich G, Nishijima D, Utter GU. Older adults with isolated rib fractures do not require routine intensive care unit admission. J Surg Res. 2020; 245:492-9.
13. Hee BP, Sung YH, Jin JK. Prognosis of pulmonary function in patients with multiple rib fractures. J Trauma Inj. 2017;30(4):179-85.

14. Mastroianni, S. Implementing a rib fracture management pathway and PIC Scoring tool to reduce ICU readmissions. Master's Projects and Capstones. 2015. p. 110-24. Available from: https: //repository. usfca.edu/capstone/110/ 